\title{
Iron Corrosion Green Inhibition in a 3\% NaCl Solution, by Leaves Extract from Pistacia Terebinthus $L$. Growing Wild in Morocco
}

\author{
M. Barbouchi, ${ }^{a, *}$ B. Benzidia, ${ }^{b}$ M. El Idrissi ${ }^{a}$ and M. Choukrad ${ }^{a}$ \\ ${ }^{a}$ Laboratory of Molecular Chemistry and Natural Substances, Moulay Ismail University, Faculty of \\ Science, P.O.Box 11201 Zitoune, Meknes-Morocco. \\ ${ }^{b}$ Laboratory of Materials, Electrochemistry and Environment (LMEE), Department of Chemistry, \\ Faculty of Science, Ibn Tofail University, P.O.Box 133, 14000. Kenitra-Morocco
}

Received February 10, 2018; accepted September 13, 2018

\begin{abstract}
In the present paper, the methanol extract from the leaves of Pistacia terebinthus L. (PT) was characterized by GC/MS analysis. It was tested as a corrosion inhibitor for iron in a $3 \% \mathrm{NaCl}$ solution, using gravimetric measurements and electrochemical methods (potentiodynamic polarizations and electrochemical impedance spectroscopy). Fourteen compounds were identified; the major compounds are palmitic acid (31.5\%), stearic acid $(25.7 \%)$ and oleic acid (11.3\%). The data showed that the tested extract offers good corrosion resistance. The constituents of the PT extract affected polarization resistance $\left(\mathrm{R}_{\mathrm{p}}\right)$ and corrosion current density ( $\left.\mathrm{i}_{\mathrm{corr}}\right)$, demonstrating that the proposed inhibitor hinders corrosion reactions. The results obtained at $200 \mathrm{ppm}$ are very interesting, and reach maximum values of $96.96 \%, 89 \%$ and $64.82 \%$, respectively, which were confirmed by scanning electron microscopy (SEM), coupled with energy scattering of X-ray spectroscopy (EDX).
\end{abstract}

Keywords: Pistacia terebinthus L., GC/MS, corrosion inhibitor, iron.

\section{Introduction}

The Pistacia genus belonging to the family of Anacardiaceae includes plants for food, medicinal, and ornamental purposes. The genus consists of about twenty species that include evergreen or deciduous, shrubs and small trees ranging from 5 to 15 meters tall [1]. The traditional pharmacopoeia uses the various parts of Pistacia species including resin, leave, fruit, and aerial part. Among them, $P$. vera, $P$. khinjuk, $P$. terebinthus $P$. atlantica, and $P$. lentiscus have been used for a long time as useful remedies for different diseases. However, P. terebinthus has been habitually used for its anti-wound medicinal activity, and treatment of brain

\footnotetext{
* Corresponding author. E-mail address: med.barbouchi08@gmail.com
} 
and gastrointestinal disorders [2]. The problem of corrosion is a primary concern that must be confronted for safety, environmental and economic reasons. It also leads to heavy maintenance environmental costs and impacts of several billion dollars [3-4].

In recent years, particularly in developing countries, corrosion research has focused on the development of "green corrosion inhibitors", of which compounds have good inhibition efficiency, without environmental impact [5-7], and reduced maintenance costs [8].

It is in this context that we have studied iron corrosion inhibition in $3 \% \mathrm{NaCl}$, by the methanol extract of PT leaves, using gravimetric and electrochemical methods to determine its inhibitory efficiency and mode of action. The anticorrosion ability of the proposed inhibitors was further examined using SEM and EDX.

\section{Materials and methods}

\section{Plant and extraction procedure}

The leaves of Pistacia terebinthus L. were collected from Moulay Idriss Zerhoun City (Morocco), in October. PT air-dried leaves were grounded in a mechanic grinder to a fine powder, and extracted by Soxhlet equipment with methanol during $6 \mathrm{~h}$, in about $300 \mathrm{~mL}$. The organic phase was filtered and evaporated under vacuum, to give the crude extract.

\section{Gas chromatographic - mass spectral analysis}

The analyzes were carried out using Clarus® SQ 8C Gas chromatograph, coupled with a mass spectrometer (GC/MS) from PerkinElmer, equipped with a Rxi-5MS capillary column $(30 \mathrm{~m} \times 0.25 \mathrm{~mm} \times 0.25 \mu \mathrm{m})$. The carrier gas was helium, with a flow rate of $1 \mathrm{~mL} / \mathrm{min}$. The oven temperature for the first $2 \mathrm{~min}$ was kept at $40{ }^{\circ} \mathrm{C}$, and then increased at a rate of $4{ }^{\circ} \mathrm{C} / \mathrm{min}$, until reaching a temperature of $180{ }^{\circ} \mathrm{C}$; and from 180 to $300{ }^{\circ} \mathrm{C}$, at a rate of $20^{\circ} \mathrm{C} / \mathrm{min}$, and then it was kept constant at $300{ }^{\circ} \mathrm{C}$, for $2 \mathrm{~min}$. The injector temperature was also set at $220{ }^{\circ} \mathrm{C}$, and split $1 / 20$ of $1 \mu \mathrm{L}$ was injected. The conditions of the mass spectrometer were $70 \mathrm{eV}$ potential ionized, and the source temperature was 200 ${ }^{\circ} \mathrm{C}$. The chemical components of the methanol extract were identified by their retention indices mass fragmentation patterns with those on the stored NIST library-version 2014.

\section{Gravimetric measurements}

Gravimetric measurements were made in glass vials containing $25 \mathrm{~mL}$ of the inhibitor. The used iron samples were accurately weighed and immersed 24 hours in $3 \% \mathrm{NaCl}$, in the absence and presence of different inhibitory concentrations. From these measurements, the corrosion rate, W $\left(\mathrm{g} \cdot \mathrm{cm}^{-2} \cdot \mathrm{h}^{-1}\right)$, and inhibition efficiency, ${ }^{\mathrm{WL}}(\%)$, were calculated by the following expressions (1 and 2): 


$$
W=\left[\frac{m_{i}-m_{f}}{S t}\right] \quad \text { (1) } \quad \eta_{W L}(\%)=\left[\frac{W^{\circ}-W}{W^{\circ}}\right] \times 100
$$

where $m_{i}$ is the initial mass, $m_{f}$ is the final mass, $S$ is the area of the sample in $\mathrm{cm}^{2} ; \mathrm{t}$ is the immersion time, and $\mathrm{W}^{\circ}$ and $\mathrm{W}$ are the corrosion rates without and with inhibitor, respectively.

The measurement of the iron ions passed in the solution was carried out by Varian Spectra AA 220 atomic absorption spectroscopy. In order to determine the concentration of iron ions in our samples by atomic absorbance, the corrosive medium was solubilized with aqua regia.

\section{Electrochemical measurements}

Impedance and polarization measurements were recorded using a three-electrode cell (potentiostat/galvanostat SP-200 "Biologic Science instruments") controlled with analysis software (VoltaMaster 4). The frequency range for the transitory method (EIS) was $100 \mathrm{kHz}$ to $10 \mathrm{mHz}$, with an applied potential signal amplitude of $10 \mathrm{mV}$. The polarization resistance $\left(\mathrm{R}_{\mathrm{p}}\right)$ was determined from the diameter of the semicircle in the Nyquist representation. Based on this, the inhibition efficiency was calculated from the following equation (3):

$$
\eta_{E I S}(\%)=\left[\frac{R_{\mathrm{p}(\text { inh })}-R_{\mathrm{p}}}{R_{\mathrm{p}(\mathrm{inh})}}\right] \times 100
$$

where $R_{p}$ and $R_{p(i n h)}$ are the polarization resistances without and with inhibitors, respectively.

The cathodic and anodic polarization curves were registered in a range from -1.2 to $0.2 \mathrm{~V}$, with a scan rate equal to $1 \mathrm{mV} / \mathrm{s}$. Before polarization scans, the electrode was stabilized at open circuit potential (OCP) for $30 \mathrm{~min}$. Inhibition efficiency rPDP (\%) Was determined by the following relationship:

$$
\eta_{\mathrm{PDP}}(\%)=\left[1-\frac{i_{\text {corr }}}{i_{\text {corr }}^{\circ}}\right] \times 100
$$

where $i_{\text {corr }}^{\circ}$ and $\mathrm{i}_{\text {corr }}$ are the corrosion current density values without and with inhibitor, respectively.

\section{Surface analysis by SEM/EDX}

The morphological characterization of the iron coupons surface was performed by scanning electron microscopy (SEM) and energy scattering X-ray spectroscopy, EDX, (flash X-ray model 6130 Bruker brand) performed in a FEI microscopy (model quanta FEG 450). 


\section{Results and discussion}

\section{Chemical composition}

The chemical composition found by GC/MS of the methanol extract of PT leaves shows fourteen compounds $(94.1 \%)$; the main constituents are palmitic acid (31.5\%), stearic acid (25.7\%) and oleic acid (1.3\%). Quantitative and qualitative analytical results are presented in Table 1.

Table 1. Chemical composition of the methanol extract of PT leaves.

\begin{tabular}{|c|c|c|c|}
\hline $\begin{array}{l}\text { Retention } \\
\text { time (min) }\end{array}$ & Name of compounds & $\begin{array}{l}\text { Molecular } \\
\text { formula }\end{array}$ & $\begin{array}{c}\text { Area } \\
(\%)\end{array}$ \\
\hline 17.40 & Pyranone & $\mathrm{C}_{5} \mathrm{H}_{4} \mathrm{O}_{2}$ & 0.7 \\
\hline 39.57 & Palmitic acid & $\mathrm{C}_{16} \mathrm{H}_{32} \mathrm{O}_{2}$ & 31.5 \\
\hline 40.92 & Oleic acid & $\mathrm{C}_{18} \mathrm{H}_{34} \mathrm{O}_{2}$ & 11.3 \\
\hline 41.07 & Stearic acid & $\mathrm{C}_{18} \mathrm{H}_{36} \mathrm{O}_{2}$ & 25.7 \\
\hline 41.43 & Bis (2-ethylhexyl) fumarate & $\mathrm{C}_{20} \mathrm{H}_{36} \mathrm{O}_{4}$ & 1.6 \\
\hline 42.53 & 1,2-Dipalmitin & $\mathrm{C}_{35} \mathrm{H}_{68} \mathrm{O}_{5}$ & 1.4 \\
\hline 42.64 & $\begin{array}{c}3 \beta-[(6-D e o x y-3-O-m e t h y l-\alpha-D-a l l o p y r a n o s y l) \text { oxy }] \\
\text {-1 } \beta, 14 \text {-dihydroxycarda-4,20(22)-dienolide }\end{array}$ & $\mathrm{C}_{30} \mathrm{H}_{44} \mathrm{O}_{9}$ & 1.8 \\
\hline 42.71 & 3-Acetoxy-7,8-epoxylanostan-11-ol & $\mathrm{C}_{32} \mathrm{H}_{54} \mathrm{O}_{4}$ & 2.2 \\
\hline 43.18 & $\begin{array}{l}\text { 21-Acetoxy-6 } \beta, 11 \beta \text {-dihydroxy-16 } \alpha, 17 \alpha \text { - } \\
\text { propylmethylenedioxpregna-1,4-diene-3,20-dione }\end{array}$ & $\mathrm{C}_{27} \mathrm{H}_{36} \mathrm{O}_{8}$ & 3.4 \\
\hline 43.55 & 1-n-Hexadecylindan & $\mathrm{C}_{25} \mathrm{H}_{42}$ & 2.0 \\
\hline 43.68 & Fluprednisolone & $\mathrm{C}_{21} \mathrm{H}_{27} \mathrm{FO}_{5}$ & 1.7 \\
\hline 44.06 & Arenobufagin & $\mathrm{C}_{24} \mathrm{H}_{32} \mathrm{O}_{6}$ & 2.2 \\
\hline 44.79 & Cholesta-4,6-dien-3-ol & $\mathrm{C}_{27} \mathrm{H}_{44} \mathrm{O}$ & 1.9 \\
\hline \multirow[t]{2}{*}{44.91} & Cholesteryl tetradecanoate & $\mathrm{C}_{41} \mathrm{H}_{72} \mathrm{O}_{2}$ & 6.6 \\
\hline & & & 94.1 \\
\hline
\end{tabular}

\section{Gravimetric measurements}

The corrosion rate values and the percentage of the inhibition efficiency were determined by the gravimetric method, for the different PT extract concentrations, after $24 \mathrm{~h}$ of immersion. The iron ions (ppm) concentrations determined by flame atomic absorbance are presented in Table 2.

Table 2. Corrosion rate values, percentage of inhibition efficiency and iron ions concentrations of the inhibitors.

\begin{tabular}{cccccc}
\hline & $\mathbf{3 \%} \mathbf{~ N a C l}$ & $\mathbf{2 5} \mathbf{~ p p m}$ & $\mathbf{5 0} \mathbf{~ p p m}$ & $\mathbf{1 0 0} \mathbf{~ p p m}$ & $\mathbf{2 0 0} \mathbf{~ p p m}$ \\
\hline$\Delta \mathrm{m}(\mathrm{g})$ & 0.132 & 0.099 & 0.042 & 0.02 & 0.004 \\
$W\left(\mathrm{mg} \cdot \mathrm{cm}^{-2} \cdot \mathrm{h}^{-1}\right) \times 10^{-6}$ & 823.35 & 617.51 & 261.97 & 124.75 & 24.95 \\
$\boldsymbol{\eta}_{\boldsymbol{W L}}$ & --- & 25.00 & 68.18 & 84.84 & 96.96 \\
Iron ions concentration $(\mathrm{ppm})$ & 87.14 & 69.28 & 52.24 & 35.74 & 18.76 \\
\hline
\end{tabular}

Table 2 shows that the corrosion rate decreases with the increase in the inhibitor concentration, reaching a value of $24.95 \times 10^{-6}$, for a concentration of $200 \mathrm{ppm}$, corresponding to an efficiency of $96.96 \%$, at the same concentration. 
For the flame atomic adsorption analyzes, the results confirm those obtained by the gravimetric method, and the iron ions concentration decreases as a function of the inhibitor concentrations; this allowed us to conclude that the PT extract has a good inhibitive property for iron corrosion in a $3 \% \mathrm{NaCl}$ solution.

\section{Potentiodynamic polarization}

The potentiodynamic polarization curves (determined via the EC-Lab software) of iron, without and with different concentrations of the PT extract in $3 \% \mathrm{NaCl}$, are indicated in Fig. 1. The useful corrosion kinetics, namely the corrosion potential ( $\left.E_{\text {corr }}\right)$, the anodic Tafel slope $\left(\beta_{\mathrm{a}}\right)$, the cathodic Tafel slope $\left(\beta_{\mathrm{c}}\right)$, and the corrosion current density $\left(i_{\text {corr }}\right)$ were obtained from the polarization curves, and are listed in Table 3.

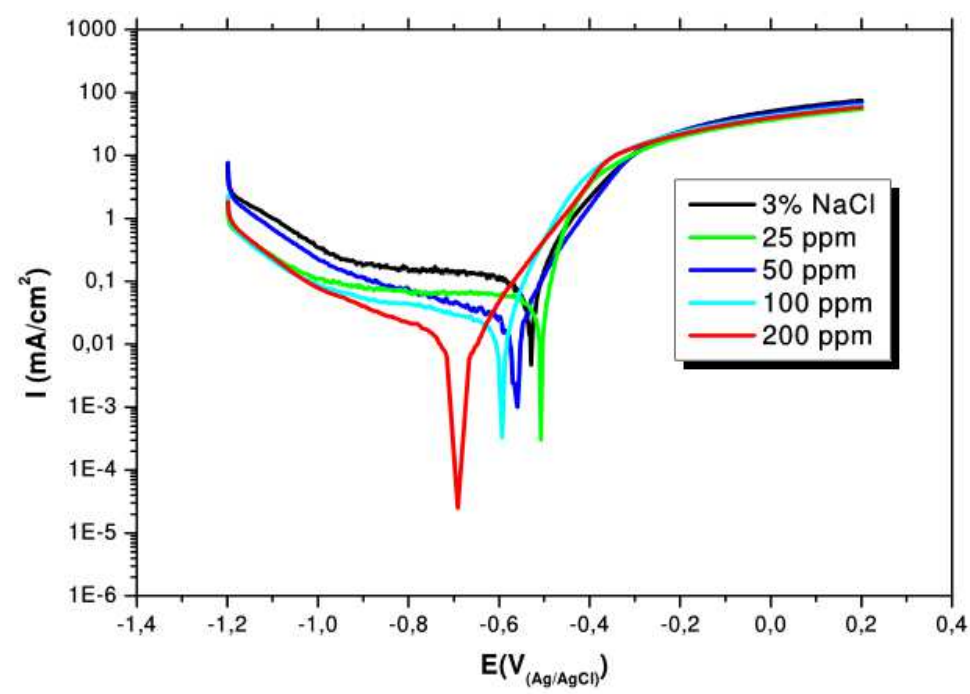

Figure 1. Potentiodynamic polarization curves for iron, without and with different concentrations of the PT extract, in a $3 \% \mathrm{NaCl}$ solution

Table 3. Tafel polarization parameters of iron in $3 \% \mathrm{NaCl}$, with various concentrations of the PT extract.

\begin{tabular}{|c|c|c|c|c|c|}
\hline $\begin{array}{c}\text { Concentration } \\
(\mathbf{p p m})\end{array}$ & $\begin{array}{l}-E_{\text {corr }} \\
(\mathbf{m V})\end{array}$ & $\begin{array}{c}i_{\text {corr }} \\
\left(\mu \mathrm{A} / \mathbf{c m}^{2}\right)\end{array}$ & $\begin{array}{c}-\boldsymbol{\beta}_{\mathbf{c}} \\
(\mathbf{m V / d e c})\end{array}$ & $\begin{array}{c}\boldsymbol{\beta}_{\mathbf{a}} \\
(\mathbf{m V} / \mathbf{d e c})\end{array}$ & $\begin{array}{r}\eta_{P D P} \\
(\%)\end{array}$ \\
\hline $3 \% \mathrm{NaCl}$ & 527.51 & 78.23 & 464.4 & 76.5 & - \\
\hline 25 & 505.82 & 32.88 & 267.8 & 38 & 58 \\
\hline 50 & 561.44 & 25.05 & 512.6 & 86.7 & 68 \\
\hline 100 & 593.27 & 19.15 & 545.3 & 66.8 & 75 \\
\hline 200 & 686.05 & 8.07 & 236.1 & 107.6 & 89 \\
\hline
\end{tabular}

Tafel polarization curves show that the PT extract adsorption onto the iron surface causes a moderate decrease in current density ( $i_{\text {corr }}$ ). The PT extract addition to a $3 \% \mathrm{NaCl}$ solution shifts corrosion potentials to a more negative direction, compared to $\mathrm{E}_{\text {corr }}$. It can be observed that the PT extract significantly blocks the cathodic reaction, while it has a limited effect on the anodic reaction. The area of the Tafel cathodic branch that appears from -0.6 to $-0.9 \mathrm{~V} / \mathrm{SCE}$ can be attributed, in neutral solutions, to oxygen reduction reaction under diffusion control. Hence, the diffusion pathway, $\mathrm{O}_{2}$, is further hindered, resulting in a more 
effective protection of the iron surface against corrosion. The increase in the inhibitor concentration results in a reduction in the $i_{\text {corr }}$, and in an increase in the inhibition efficiency (Table 3), which suggests that, at higher inhibitor concentrations, a complete protective film tends to be formed. As it can be seen, both anodic and cathodic Tafel slopes were changed by the PT extract addition, evidencing that the extract constituents affect both anodic and cathodic reactions. The slight reduction in $\beta_{\mathrm{a}}$ refers to the limiting of metal dissolution [9-10]. Table 3 shows that the inhibition efficiency increased from $58 \%$, at $25 \mathrm{ppm}$, to $89 \%$, at 200 ppm.

\section{Electrochemical impedance spectroscopy measurements}

The iron impedance diagrams in $3 \% \mathrm{NaCl}$ were plotted after $30 \mathrm{~min}$ of immersion, in the absence and presence of the PT extract. The results are shown in Fig. 2. This figure shows that the Nyquist plots of iron, in uninhibited and inhibited solutions, have a semicircular shape. Although the appearance of Nyquist plots remained the same, their diameter increased after the inhibitor addition to the corrosive solution. This increase was more and more pronounced with increasing concentrations of the PT inhibitor. The appearance of inductive semicircles in the Nyquist plot, when no inhibitor is added, can be attributed to the molecular diffusion of oxygen through a porous layer built up by corrosion, which is the reaction limiting step [11]. When the PT extract is added to the solution, the effect of the inductive loop is reduced and, at high concentrations, only one capacitive loop remains.

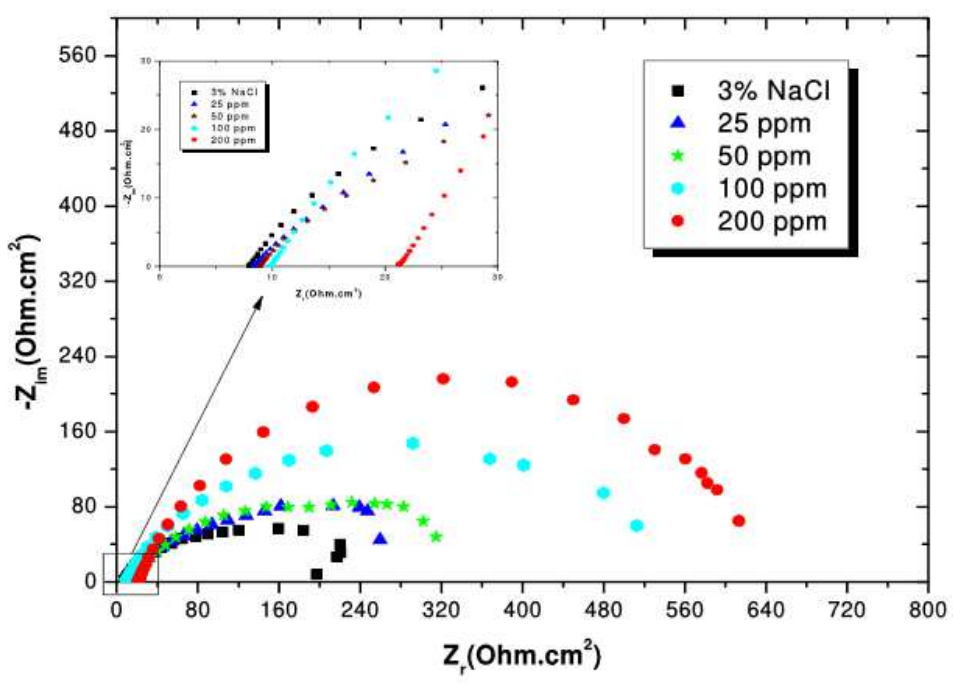

Figure 2. Plots of impedance spectra for iron in $3 \% \mathrm{NaCl}$, in the absence and presence of the PT extract.

The equivalent circuit depicted in Fig. 3 is employed to analyze the impedance spectra. In this circuit, $\mathrm{R}_{1}$ represents the resistance to the solution, placed in series with the resistance of the film due to the surface film $\left(R_{2}\right) . Q_{1}$ is the capacitance due to the dielectric nature of the surface film, $R_{3}$ is the resistance to the transfer of charge related to the corrosion process and $\mathrm{Q}_{3}$ is a constant phase 
element representing the capacity of the double layer at the interface between the metal and the solution.

The electrochemical parameters derived from these curves were determined via the EC-Lab software. From the impedance data given in Table 4, we note that the inhibitor introduction into the $3 \% \mathrm{NaCl}$ solution caused the polarization resistance to increase, while reducing the double-layer capacitance and, consequently, the inhibition efficiency increased to $64.82 \%$, at a concentration of $200 \mathrm{ppm}$. This effect becomes more pronounced at higher concentrations. This increase in the diameter of the Nyquist semicircle points towards improved corrosion resistance, due to the corrosion-inhibiting action of the extract constituents. The decrease in $\mathrm{Q}_{\mathrm{dl}}$ arises from a decrease in local dielectric constant and/or an increase in the thickness of the electric double layer, implying that the water molecules and the electrolyte ions penetrate more into the metal surface [12-13].

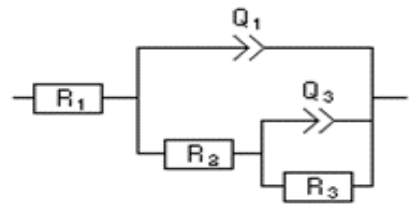

Figure 3. The equivalent circuit model.

Table 4. Electrochemical parameters calculated from EIS measurements for iron in 3\% $\mathrm{NaCl}$, in the absence and presence of different PT extract concentrations.

\begin{tabular}{|c|c|c|c|c|c|c|c|c|c|c|}
\hline & $\begin{array}{c}\mathbf{C} \\
(\mathbf{p p m})\end{array}$ & $\begin{array}{c}\mathbf{R}_{\mathbf{1}} \\
(\mathbf{O h m})\end{array}$ & $\begin{array}{c}\mathbf{R}_{\mathbf{2}} \\
(\mathbf{O h m})\end{array}$ & $\begin{array}{l}Q_{1 \times 10^{-3}} \\
F_{S^{(n-1)}}\end{array}$ & $\mathbf{n}_{1}$ & $\begin{array}{c}\mathbf{R}_{\mathbf{3}} \\
(\mathbf{O h m})\end{array}$ & $\begin{array}{l}\mathbf{Q}_{2 \times 10^{-3}} \\
\text { F s }^{(n-1)}\end{array}$ & $\mathbf{n}_{2}$ & $\begin{array}{c}\mathbf{R}_{\mathbf{p}} \\
(\mathbf{O h m})\end{array}$ & $\underset{\%}{\eta_{E I S}}$ \\
\hline \multirow{2}{*}{$3 \% \mathrm{NaCl}$} & & 7.811 & 87.56 & 1.109 & 0.730 & 128.6 & 6.574 & 0.935 & 216.1 & - \\
\hline & 25 & 8.245 & 174.5 & 0.645 & 0.640 & 187.6 & 3.448 & 0.589 & 362.1 & 40.3 \\
\hline \multirow[t]{3}{*}{ PT } & 50 & 8.937 & - & - & - & 375.7 & 3.111 & 0.966 & 375.7 & 42.5 \\
\hline & 100 & 9.520 & - & - & - & 503.9 & 0.517 & 0.697 & 503.9 & 57.11 \\
\hline & 200 & 21.21 & - & - & - & 614.4 & 0.373 & 0.774 & 614.4 & 64.82 \\
\hline
\end{tabular}

\section{Effect of immersion time}

The evolution of electrochemical impedance diagrams at different iron immersion times in $3 \% \mathrm{NaCl}$, in the presence of $200 \mathrm{ppm}$ of the PT extract, is shown in Fig. 4.

Fig. 4 shows that the electrochemical impedance diagrams at different immersion times are similar, except for the difference in the loops diameter. The results show that the PT extract acts at low concentrations, by the formation of a barrier layer reinforced by corrosion products, protecting the metal substrate.

\section{Surface analysis by SEM/EDX}

The evaluation of the morphology of the metal surface was done to prove whether the inhibition is due to the formation of an inhibitor film on the metal surface. The electrode surface was investigated by scanning electron microscopy 
(SEM), coupled with EDX, after $24 \mathrm{~h}$ immersion in $3 \% \mathrm{NaCl}$, in the absence and presence of 200 ppm of the PT extract. The results are presented in Fig. 5.

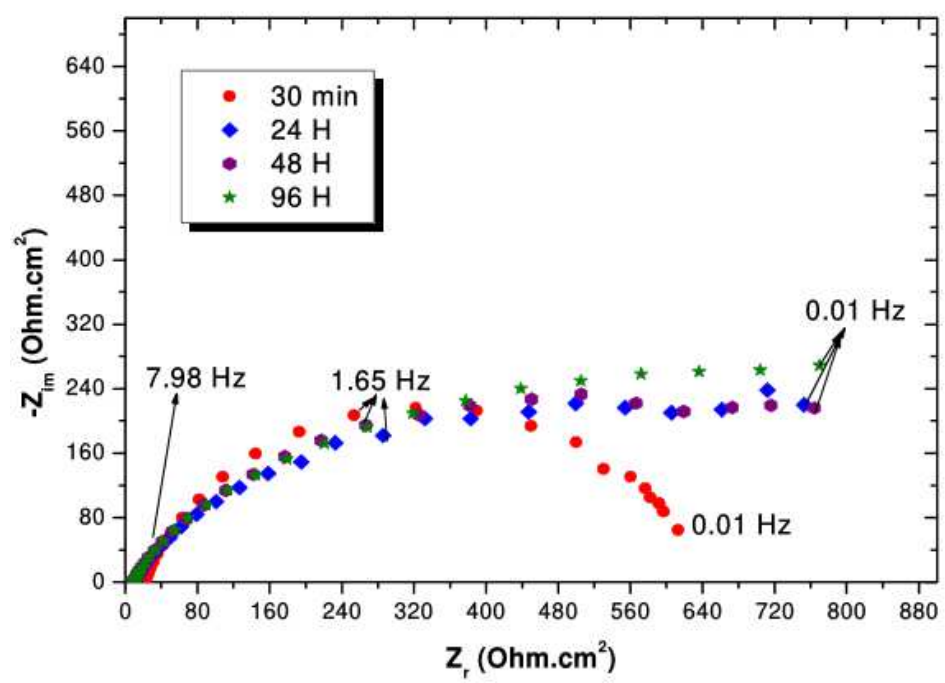

Figure 4. Electrochemical impedance diagrams of iron in $3 \% \mathrm{NaCl}$, in the presence of $200 \mathrm{ppm}$ of the PT extract, for different immersion times.
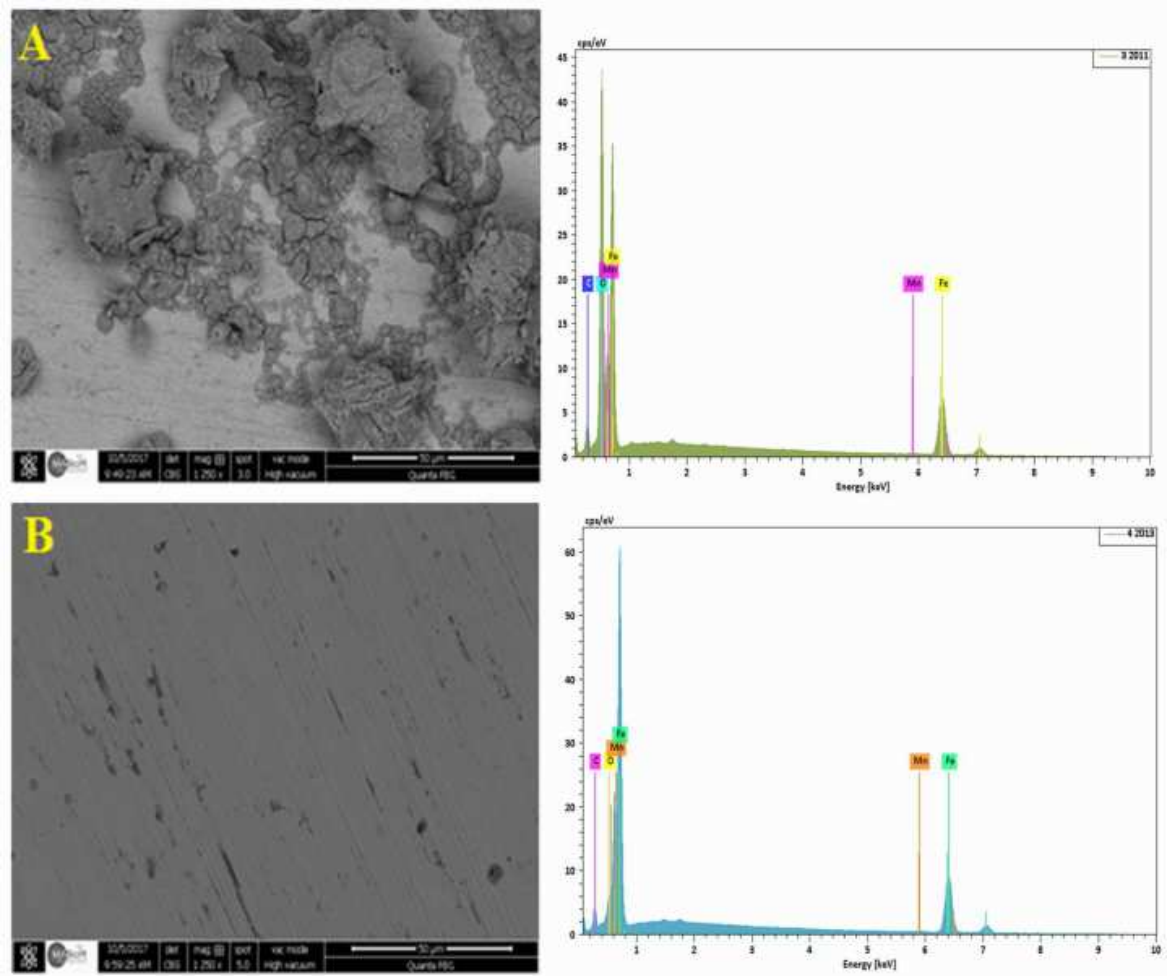

Figure 5. SEM/EDX micrographs of iron, in a $3 \% \mathrm{NaCl}$ solution, after $24 \mathrm{~h}$ of immersion time: (A) after immersion without inhibitor; and (B) after immersion with 200 ppm of the PT extract.

On the one hand, the iron surface, after $24 \mathrm{~h}$ of immersion in the corrosive medium (Fig. 5 (A)), clearly shows the attack on the metal surface by the aggressive ions, and the development of several corrosion sites. On the other hand, in the PT extract presence, we find, through the SEM image of the steel 
surface, after the same immersion time (figure 5(B)), that it is uniformly covered with an apparently thin layer product that testifies the formation of an inhibitor film on the electrode surface. This result is in agreement with the electrochemical measurements.

The development of several corrosion sites has been confirmed by the EDX analysis, where a high level of oxygen has been recorded in the inhibitor absence. The corrosion products form a film on the electrode surface in oxygen presence. In the PT extract presence, the percentage of carbon increases, because it is related to the chemical composition of the inhibitor, and the oxygen peak remarkably decreases, indicating the inhibitor adsorption onto the metal surface, which leads to the creation of a film that limits the formation of oxides.

\section{Conclusions}

From the overall experimental results, the methanol extract of Pistacia terebinthus leaves is rich in several acid constituents, such as palmitic acid $(31.5 \%)$, stearic acid $(25.7 \%)$ and oleic acid (11.3\%).

The data obtained from the three different methods - gravimetric, potentiodynamic polarization and electrochemical impedance spectroscopy measurements - were in good agreement. Corrosion parameter data have shown that the PT extract acts as a cathodic inhibitor which retards the cathodic process by changing the corrosion process mechanism. The results of the surface analysis, using SEM coupled with EDX, showed the formation of a protective layer on the iron surface, in the inhibitor presence. The selection of the inhibitor is important for environmental protection, and the methanol extract from the PT leaves proved to be a green corrosion inhibitor for iron, in a $3 \% \mathrm{NaCl}$ solution.

\section{References}

1. Rauf A, Patel S, Uddin G, et al. Phytochemical, ethnomedicinal uses and pharmacological profile of genus Pistacia. Biomed Pharmacother. 2017;86:393.

2. Bozorgi M, Memariani Z, Mobli M, et al. Five Pistacia species (P. vera, P. atlantica, $P$. terebinthus, $P$. khinjuk, and $P$. lentiscus): A review of their traditional uses, phytochemistry, and pharmacology. Sci World J. 2013;2013:1.

3. Srivastava V, Haque J, Verma C, et al. Amino acid based imidazolium zwitterions as novel and green corrosion inhibitors for mild steel: Experimental, DFT and MD studies. J Mol Liq. 2017;244:340.

4. Ostovari A, Hoseinieh SM, Peikari M, et al. Corrosion inhibition of mild steel in $1 \mathrm{M} \mathrm{HCl}$ solution by henna extract: A comparative study of the inhibition by henna and its constituents (Lawsone, Gallic acid, $\alpha$-d-Glucose and Tannic acid). Corros Sci. 2009;51:1935.

5. Dermaj A, Chebabe D, Doubi M, et al. Inhibition of bronze corrosion in $3 \%$ $\mathrm{NaCl}$ media by novel non-toxic 3-phenyl-1,2,4-triazole thione formulation. Corros Eng Sci Techn. 2015;50:128. 
6. Left DB, Zertoubi M, Khoudali S, et al. New Application of Chamaerops Humilis L . Extract as a Green Corrosion Inhibitor for Reinforcement Steel in a Simulated Carbonated Concrete Pore Solution. Port Electrochim Acta. 2018;36:249.

7. Hassannejad H, Nouri A. Sunflower seed hull extract as a novel green corrosion inhibitor for mild steel in $\mathrm{HCl}$ solution. J Mol Liq. 2018;254:377.

8. Sharma SK. Green corrosion chemistry and engineering: opportunities and challenges. Germany: Wiley-VCH; 2012.

9. Babic-Samardžija K, Khaled KF, Hackerman N. Heterocyclic Amines and Derivatives as Corrosion Inhibitors for Iron in Perchloric Acid. Anti-Corros Method Mater. 2005;52:11.

10. Ebadi M, Basirun WJ, Khaledi H, et al. Corrosion inhibition properties of pyrazolylindolenine compounds on copper surface in acidic media. Chem Central J. 2012;6:1.

11. Usman BJ, Umoren SA, Gasem ZM. Inhibition of API 5L X60 steel corrosion in $\mathrm{CO}_{2}$-saturated $3.5 \% \mathrm{NaCl}$ solution by tannic acid and synergistic effect of KI additive. J Mol Liq. 2017;237:146.

12. Gupta NK, Quraishi MA, Verma C, et al. Green Schiff's bases as corrosion inhibitors for mild steel in $1 \mathrm{M} \mathrm{HCl}$ solution: experimental and theoretical approach. RSC Advances. 2016;6:102076.

13. Yadav M, Sinha RR, Sarkar TK, et al. Corrosion inhibition effect of pyrazole derivatives on mild steel in hydrochloric acid solution. J Adhes Sci Technol. 2015;29:1690. 